\title{
Logistics 4.0 Skills Requirements: Evidence from a Developing Country
}

\author{
Abdelghani Benayoune ${ }^{1}$, Abdelsalam Adam Hamid ${ }^{1 *}$, Noorul Shaiful Fitri Abdul Rahman², Khalid Al \\ Kalbani $^{1}$, and Zouhaier Slimi ${ }^{1}$ \\ ${ }^{1}$ Department of Logistics Management, International Maritime College Oman, Sohar, Sultanate of Oman; and ${ }^{2}$ Higher \\ Colleges of Technology, Abu Dhabi, United Arab Emirates. \\ *Correspondence: abdelsalam@imco.edu.om (Dr. Abdelsalam Adam Hamid, Professor, Dept. of Logistics Management, \\ International Maritime College Oman, Sohar, Sultanate of Oman).
}

\begin{abstract}
Robotics, artificial intelligence (AI) and the Internet of Things are new technologies that are changing the world and mainly logistics companies in increasing competitiveness and effective operation. However, these technologies bring about significant changes in many industries, including the logistics industry. A skilled workforce is vital to the industry's competitiveness. Therefore, insufficient skills are often considered a solid barrier to Industry 4.0 implementation. This paper assesses the requirements of logistics 4.0 Skills from an Omani industrial perspective by providing empirical evidence of Industry 4.0 skills requirement in the logistics industry in Oman. An experimental methodology based on a survey has been implemented to gather valid thorough evidence. The survey was distributed to approvability sample (random sample) of logistics companies in Oman. The findings recommend that critical stakeholders align education output with industry needs and outline policy directions to prepare the domestic workforce for the future in the logistics industry.
\end{abstract}

Keywords: Education, Future skills, Industry 4.0, Logistics, Supply chain, and Workforce development.

\section{INTRODUCTION:}

The economy of Oman is heavily dependent on hydrocarbon revenue. The oil and gas industry constituted $34.4 \%$ of the nominal GDP and $76 \%$ of the government revenues in 2019 (CBO, 2020). Through its National Program for Enhancing Economic Development (Tanfeed), the country aims to diversify economic sources of the hydrocarbon industry through five sectors: manufacturing, tourism, mining, fisheries, and transport and logistics. This paper concentrates on the logistics sector embedding the five above mentioned sources. Logistics, in particular, is set to play a significant role in economic diversification initiatives (Tanfeed, 2016). According to Tanfeed, (2016) the logistics industry includes activities such as transportation of materials, finished goods or components of the supply chain, forwarding operation related to facilitating import and export roles, warehousing storing and controlling materials, components and finished goods at each supply chain UniversePG I www.universepg.com stage. Additionally, value added logistics services and other value-added servicesincludepacking, sorting, quality assurance, batching, and tracking. The Logistics Strategy 2040 (SOLS, 2015) was designed to transform Oman into a world logistics hub. The implementation of this strategy is expected to contribute $12 \%$ of the overall GDP by 2040 and create more than 300,000 jobs. The logistics industry contributed US\$2.8 billion to its GDP in 2018. This figure is projected to reach US $\$ 36.4$ billion in 2040 (World Bank Group, 2019).

\section{Logistics 4.0}

The mechanization of production was the first industrial revolution and the introduction of the steam engine. This revolution reshaped many Industries and transformed societies. In comparison, the invention of electricity and assembly line production marked the second industrial revolution. The third industrial revolution began with the broad deployment of electrical and computer technology to autom 
ate manufacturing operations. The $4^{\text {th }}$ Industrial Revolution resulted from the rapid development of several technologies simultaneously (industry 4.0). Big data, the internet of things, cloud computing, 3D printing, autonomous robots, and cyber security are examples of these technologies. The increased use of connectivity is blurring the line between the physical, digital, and biological world (Schwab, 2016; Drath and Horch, 2014). Industry 4.0 was first made famous at the Hannover Fair of Industrial Technologies in 2011 (Pfeiffer, 2017). The implementtation of Industry 4.0 brings various corporate benefits, including operational and value chain optimization (Strange \& Zucchella, 2017). For example, data analytics is expected to improve operational efficiency in operations and enhance inventory visibility and management. The high implementation of the internet of things will improve resource planning and supply chain transparency. On the other hand, Block chain is projected to increase supply chain security and the benefits of $3 \mathrm{D}$ printing, such as reduced transportation demand (PwC, 2016).

According to MGI, (2019), the transportation and warehousing business has the third most enormous automation potential of any industrial sector. Logistics 4.0 follows the same interconnectedness and interoperability principles as Industry 4.0 (Dembiska, 2018). Logistics 4.0 has no widely acknowledged definition (Winkelhaus \& Grosse, 2020). However, in this study, Logistics 4.0 is defined as applying industry 4.0 technologies to increase operational efficiency and competitive advantage (Herhardt \& Partner, 2016; Magruk, 2016; Ezzat et al., 2019). When faced with lockdown, social isolation, and changes in customer behaviour, consumption, and expectations, the most successful businesses will most likely be those who leverage digital uptake solutions to mitigate the pandemic's disruptions. Logistics 4.0 can alter logistics companies and assist the government in diversifying its economy while solving economic issues caused by oil price instability. Previous industrial transformations wreaked havoc on the company and job landscapes. Logistics 4.0 is also projected to revolutionize the logistics and supply chain industries, resulting in significant personnel makeup and capabilities changes. It is worth noting that a lack of required competencies and skills has been recognized as a barrier to Industry 4.0 adoption (Herceg et al., 2020).
Furthermore, one of the most important goals of Oman's logistics strategy is to create jobs. However, it has been noted that there is a significant disparity between the talents required by the business and those available on the market (Sols, 2015; Tanfeed, 2016; Benayoune, 2018). Other issues in the logistics business include a lack of proper education/training programs, a negative image of the logistics sector as a vocation, a paucity of appropriately educated workers, and a high percentage of expatriates in occupations that require limited skills (Benayoune, 2018). Logistics 4.0 could help Omani logistics enterprises overcome a labour deficit (overreliance on expatriates) and improve the sector's poor image, as it has the potential to modify its appearance and create new employment prospects favourably. Workers in the logistics industry must have the necessary skills and talents for today and tomorrow. Understanding Logistics 4.0 skills requirements and preparing suitable answers are crucial for meeting skills demands and closing the potential skills supply gap.

Based on the debate above, this report examines Oman's logistics 4.0 skills requirements by identifying the most in-demand skills. These talents are now in short supply in the local market, and logistics companies assess ways to fill the gap. The study's findings can be used to start a conversation regarding the impact of technology on employment, skills, and education in the logistics industry and legislative responses. The study is part of a project called "The impact of Industry 4.0 on jobs, skills, and training in the logistics sector," which investigates a variety of Logistics 4.0 topics. Only research topics relevant to this paper's subject are mentioned. The following is the structure of the paper: $1^{\text {st }}$ an overview, $2^{\text {nd }}$ literature review, 3rd study's research approach, fourth findings and conclusions, $5^{\text {th }}$ the policy response and its repercussions and $6^{\text {th }}$ the conclusion and subsequent work.

\section{Literature review}

\section{Impact of Logistics 4.0 on jobs}

In recent years, the impact of new technology on occupations has gotten much attention. Research has shown that automation could result in mass unemployment (Bowles 2014; Frey and Osborne, 2013). On the other hand, this research believed that technology would abolish all occupations. Recent studies, however, have shown that a job consists of a series of tasks that require a diverse set of skills and com- 
petencies. According to these findings, technology's impact is more likely to be felt at the task level (Bakhshi et al., 2017; Arntz et al., 2016). According to Arntz et al. (2016), technological advancements must be viewed as complementing or substituting specific tasks rather than entire vocations. Several researches have shown that automation could result in mass unemployment. According to Frey and Osborne $(2013,2014)$, over $47 \%$ of US employment is in jeopardy. Lamb (2016) anticipates that automation would influence 42 per cent of employed Canadian labour in the next 10 to 20 years, based on Frey and Osborne's research. The composition of tasks that can be mechanized determines the number of prospective employees in danger ( $\mathrm{PwC}, 2021)$. A lesser fraction of employment may become redundant, depending on the number of functions that could become obsolete. As a result, while the requirement for labour will not disappear, the skills required will surely change. Predictable, manual operations and data processing-related employment are at a greater risk of being influenced by technology in logistics. Many jobs presently performed by material handlers, for example, are projected to be automated in the future. According to much research, low- and middle-skilled jobs are significantly dangerous to becoming auto-mated. As a result, many job functions will become obsolete. High-skilled jobs and jobs requiring a high level of social intelligence, on the other hand, are the least likely to be automated (Schröder et al., 2019; Arntz et al., 2016). Cargo and Freight Agents, Order Clerks (98 percent), Packaging and Filling Machine Operators (98 per cent), Procurement Clerks (98 percent), Retail Salesperson (91 per cent), Crane Operator (90 per cent), Postal Service Mail Carriers (68 percent), Bus Drivers (67 per cent), Purchasing Agents (77 percent), Heavy Truck Drivers (77 percent), according to Frey and Osborne, (2013) (79 percent). However, these projections should be seen with caution, as technical capabilities may not always imply economic viability (Rahman, 2021; Acemoglu and Restrepo, 2016).

The more significant the proportions of manual, repetitive work in a job, the more influence it is. The lower skilled roles are the ones that are most affected by technology. Routing ( 24.4 percent), planning (20.7\%), administration, and scheduling are among the logistics tasks that may be automated in the next five years (13.4 per cent). On the other hand, if the technology becomes more widely adopted, there will be a demand for new jobs (Schröder et al., 2019; Arntz et al., 2016; Autor, 2015). 84 percent of businesses plan to accelerate the digitalization of working processes and considerably expand remote work, according to the WEF, (2020) research. Workers who can fill jobs like cloud computing, software development, sales, and marketing are expected to demand. From warehousing to last-mile delivery, some of the most labour-intensive activities are on their way to being automated (PwC, 2016). Logistics 4.0 technologies are being used to varying degrees across the global supply chain, with warehousing having the most automation potential, MGI, (2019) and FTA, (2019). Managers and directors in transportation and distribution, transport and distribution clerks, and managers and directors in storage and warehousing are all in high demand, according to reports. Most logistics organizations in the United Kingdom (79 percent) aim to grow the number of higher skilled positions in the future. Despite this, $66 \%$ are concerned about a shortage of skilled employees to fill job openings (FTA, 2019). Data Analysts and Scientists, Digital Marketing and Strategy Specialists, Business Development Professionals, AI and Machine Learning Specialists, Digital Transformation Specialists, Process Automation Specialists, General and Operations Managers, Database and Network Professionals, and Big Data Specialists are among the most in-demand or emerging jobs in the next five years, according to WEF, (2020). Furthermore, the growing usage of warehouse management systems necessitates hiring competent warehouse workers and creating new professional roles such as remote operators.

\section{Impact of Logistics 4.0 on Skills}

As previously discussed, technological advancements will create new jobs requiring new skills. Skills are essential for long-term employability and industry competitiveness. Literature suggests workers will likely lack the new skill sets required for new jobs. Furthermore, insufficient skills coupled with the lack of technological knowledge have been identified as solid barriers to Industry 4.0 adoption in the literature (Bag et al., 2018; Mogos et al., 2019).

Besides, various studies reported a growing mismatch between graduate skills and labour market needs (Brunello and Wruuck, 2019; Benayoune, 2018; Alemu et al., 2021). Logistics 4.0 is expected 
to create an increasing skill mismatch in the sector. Literature suggests that demand for skills related to predictable and repetitive tasks are set to decrease, while demand for skills in higher cognitive and technological job-specific skills are expected to increase (Ellingrud et al., 2020; Bakhshi et al., 2017). As more and more tasks are automated, transversal skills such as problem-solving, critical thinking, creativity, self-management, active learning and flexibility are in demand (WEF, 2020). To keep pace with Logistics 4.0, digital literacy skills are increasingly in demand. The digital skills identified in the literature include data analysis, technology use, and technology design and programming, troubleshooting and user experience (WEF, 2020). As more and more tasks are automated, problem-solving, critical thinking, analysis, and creativity skills will be in demand (WEF, 2020). Various studies highlighted the importance of Science, Technology, Engineering and Mathematics (STEM) as critical for the future of jobs (Bonfield, 2020; Maisiri et al., 2019; PwC, 2018; Bakhshi et al., 2017). Other emerging skills mentioned in the literature include using and monitoring technology systems for operating machinery, understanding the endto-end supply chain to effectively find ways to leverage technology to improve operational performance, planning, and problem-solving to develop optimal network efficiency solutions. Implication for education and training. The changes in skills requirements will have a significant effect on the education and training system (Maisiri et al., 2019). The digital culture and training shortage is the greatest challenge facing transportation and logistics companies (PwC, 2016).

According to SOLS, (2015), the growth of logistics in Oman is negatively impacted by the absence of trained nationals with vocational skills and the lack of logistics and vocational training to bridge that gap. Mostly low- and mid-skilled workers are the most impacted by automation. Adjusting to Logistics 4.0 era will require efforts from all key stakeholders to support the current workforce in developing the necessary skills to transition towards the new jobs ahead. Opportunities to up skill or re skill can take a range of forms including on the job training, short courses, industry certification and formal education and training programs. Strategies to address technological changes reported in the literature involve hiring new employees with skills relevant to new technologies, re-skilling existing employees or outsourcing some business functions to external contractors (WEF, 2017). For example, 53\% of all employees in the logistics sector will require significant re-skilling and up-skilling. It is expected that $36 \%$ will require training of up to six months, while 9\% will require more than one year of additional skills training (FTA, 2019). The importance of apprenticeships or work-based learning has been highlighted to bridge the potential skills gap. The importance of lifelong learning to equip the workforce with the required skills to remain employable was also highlighted in the literature (Bakhshi et al., 2017; Maisiri et al., 2019; Ehlers \& Kellermann, 2019; Crowley et al., 2022).

Aim: aims at assessing the skills requirements of logistics 4.0 in Oman

\section{METHODOLOGY:}

This study used an experimental design. The data collection instrument used is an Office 365 Forms survey. The survey questionnaire is part of a more extensive study titled "The impact of Industry 4.0 on jobs, skills, and training in the logistics sector," which investigates various Logistics 4.0-related concerns. The poll was conducted among managers and technology specialists who have adequate skills and understanding regarding digital strategy in their organizations. Random sampling was used to ensure that data were collected without bias. The questionnaire was distributed to 150 enterprises registered with Oman's Ministry of Manpower, and a response rate of 15.33 per cent was obtained. Indeed, as shown in Table 1, around 83 per cent of participating organizations were logistics service providers, while the remainders were logistics service users. The data collection was via Microsoft Excel Data Analysis. Frequency analysis techniques were used to analyze the data.

Table 1: Respondents companies' profiles.

\begin{tabular}{|l|c|c|}
\hline & Statement & Percentage \\
\hline 1 & & Main Industries \\
\hline & Supply Chain / Logistics & $41 \%$ \\
\hline & Transportation and warehousing & $33 \%$ \\
\hline
\end{tabular}


Benayoune et al., / Canadian Journal of Business and Information Studies, 4(2), 24-36, 2022

\begin{tabular}{|c|c|c|}
\hline & Chemicals and plastics & $13 \%$ \\
\hline & Energy & $5 \%$ \\
\hline & Manufacturing & $4 \%$ \\
\hline & Wholesale & $3 \%$ \\
\hline 2 & \multicolumn{2}{|c|}{ Nature of the organization } \\
\hline & Private company & $41 \%$ \\
\hline & International company & $22 \%$ \\
\hline & State-Owned & $26 \%$ \\
\hline & Public/Government company & $7 \%$ \\
\hline & Other & $4 \%$ \\
\hline 3 & \multicolumn{2}{|c|}{ Company size } \\
\hline & 10-49 employees & $28 \%$ \\
\hline & $50-99$ & $12 \%$ \\
\hline & $100-250$ & $12 \%$ \\
\hline & $250-1000$ & $20 \%$ \\
\hline & More than 1000 & $28 \%$ \\
\hline 4 & \multicolumn{2}{|c|}{ Company experience } \\
\hline & Less than 5 years & $12 \%$ \\
\hline & $5-10$ & $24 \%$ \\
\hline & $10-20$ & $40 \%$ \\
\hline & More than 20 & $24 \%$ \\
\hline
\end{tabular}

\section{RESULTS:}

When asked about the impacts of technologies that will have on the workforce in the next five to 10 years, $44 \%$ of respondents indicated that new skills are required, while $37 \%$ of them said that it would reduce the number of staff and $14 \%$ think that new team needed as shown in Fig. 2a. When asked the impact of technology adoption had on jobs in the past five years, the majority $(80 \%)$ of respondents indicated that it improved work flexibility, while $60 \%$ of them selected "enabled increase and collaboration", $(56 \%)$ selected "redefined work" and (52\%) chose "restructured jobs" as shown in Fig. 2b. Most respondents indicated that professional level, i.e., high School and Less, such as crane drivers and equipment operators, would be most impacted by job displacements. The results align with the literature on the impact of educational and skill levels most affected by technology.

Table 2: Impact of Technology implementation on the workforce.

\begin{tabular}{|c|c|c|}
\hline & Statement & Percentage \\
\hline 1 & Impact on the workforce & $44 \%$ \\
\hline & New skills required & $37 \%$ \\
\hline & Reduced number of staff & $14 \%$ \\
\hline & New team required & Percent age \\
\hline & Increased number of staff & \multicolumn{2}{|c|}{$6 \%$} \\
\hline & Statement & $80 \%$ \\
\hline & Impact of technology on jobs in the past five years. & $56 \%$ \\
\hline & Enabled increased collaboration, & $52 \%$ \\
\hline
\end{tabular}

By combining highly agree and agree in one percentage and strongly disagree and disagree in one percentage, the following abilities are most likely to be required in logistics organizations during the next 5-10 years, based on respondents' feedback: industrial cyber security management (96 percent), data management and security (91 percent), data analytics (83

UniversePG I www.universepg.com percent), and digital marketing (83 percent) (80 per cent). Programming \& coding, as well as information and communication technologies (65.1 per cent). Inventory management skills, for example. As illustrated in Fig. 3, operational planning, project management, and supply chain security will continue to demand. 


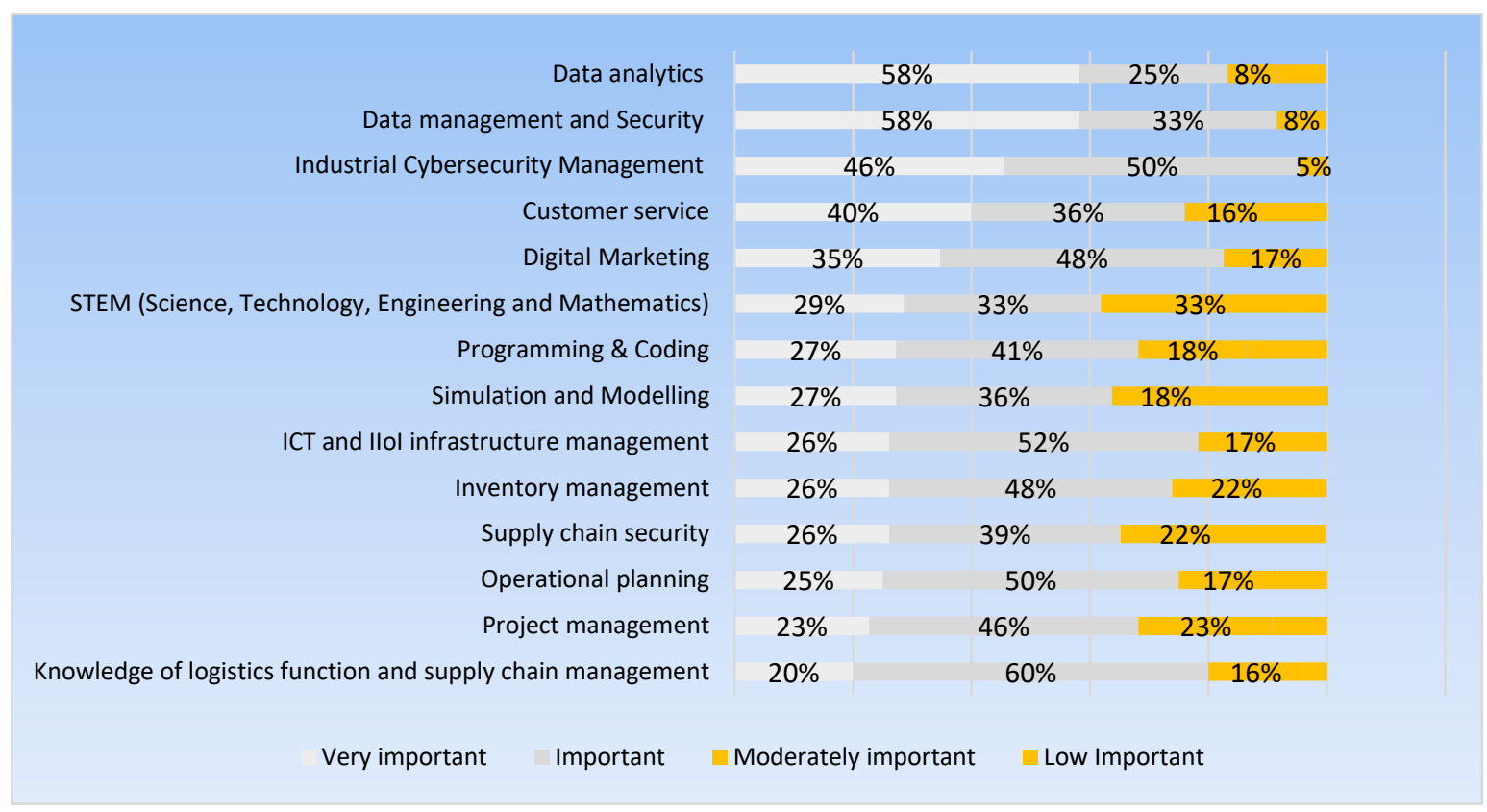

Fig. 1: Emerging skills that will be increasingly important in the next 10 years in Oman.

Since the future of work will be characterized by nonroutine tasks, soft skills such as creativity, problemsolving, and critical thinking will continue to be necessary. According to respondents, the most important fundamental skills are creativity and invention (92 per cent) and communication (92 per cent), followed by problem-solving (91 per cent), critical thinking (88 per cent), cooperation and teamwork ( 88 per cent), and collaboration and teamwork (88 per cent) (86 per cent). Additional competencies such as project management, entrepreneurialism, and lifelong learning will be required. These abilities are crucial for the work-force's future employability. The literature confirms the critical nature of this talent for future employment.

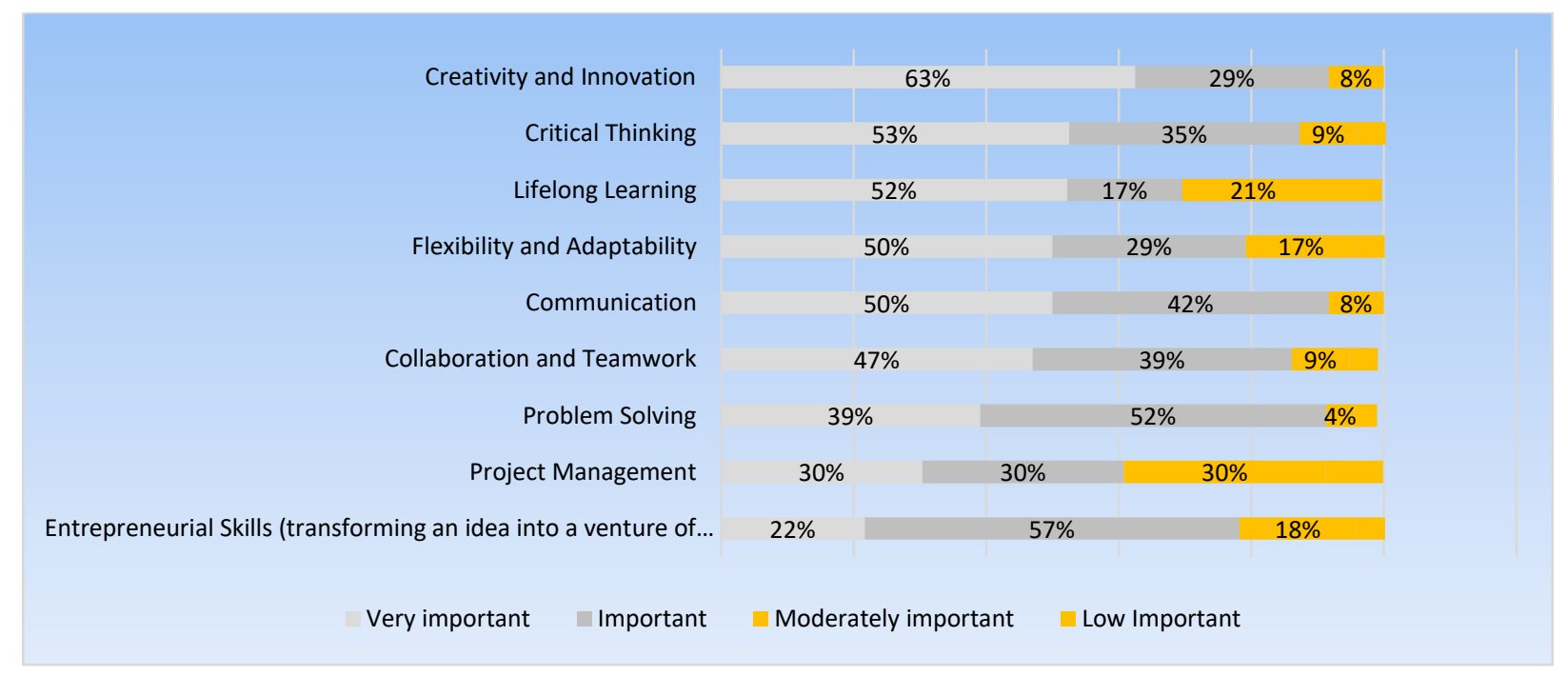

Fig. 2(a): Emerging skills that will be increasingly important in the next 10 years.

According to respondents' responses, the top skills (technical and soft skills) that are currently lacking in Oman's local marketplace are data analytics (68 per cent), digital marketing ( 52 per cent), lifelong learning (48 per cent), creativity and innovation (48 per cent), programming and coding (44 per cent), and Industrial cyber security (48 per cent), as illustrated in
Fig. 5. When it comes to the top leadership skills a manager should have to succeed in the digital era, $88 \%$ selected thinking outside the box. Being visionary was ranked second (80\%), while communication and understanding how technologies work (72\%) were ranked third. Other skills are illustrated in Fig. 6. 


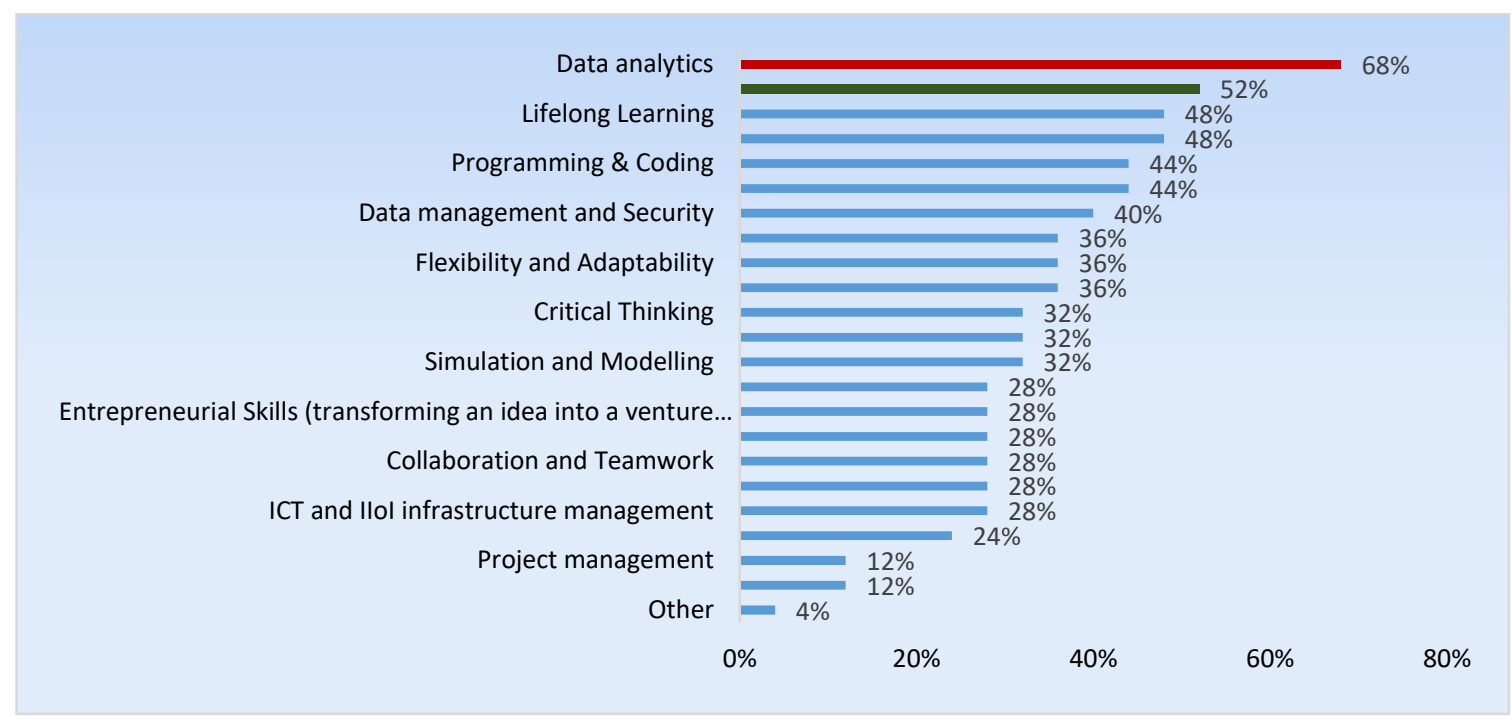

Fig. 2(b): Skills lacking in the local marketplace in Oman.

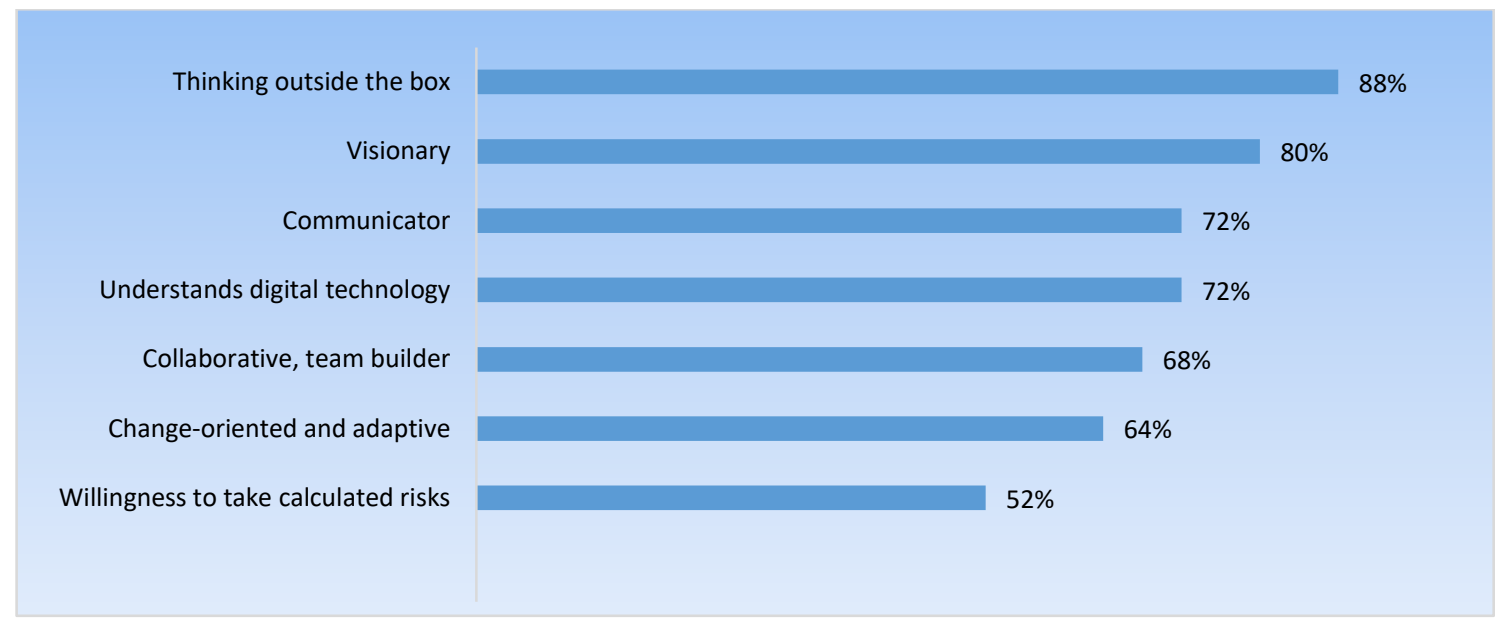

Fig. 3: Skills an organizational leader should have.

When asked about the availability of suitably qualified personnel in Oman, most respondents indicated that semi-skilled groups such as drivers and order pickers are unavailable, followed by skilled groups (those with a high school diploma or less) such as crane operators or equipment operators. These are typically low-skilled and experience-required jobs. Typically, this type of position is filled by expats prepared to work for lesser wages than citizens. The logistics sector's poor career image, combined with the private sector's reluctance to provide high wages, may explain why logistics firms in Oman heavily rely on expatriates in positions that need low qualifications (Benayoune, 2018).

To a lesser extent, (44 per cent) of respondents stated that they have no difficulty filling high-skilled jobs with graduates or post-graduates. In comparison, just $28 \%$ of respondents responded that competent groups have sufficient competence (diplomas or less) to fill supervisory, technical, and information technology technician positions. Most logistics companies have difficulty recruiting qualified applicants to fill logistics positions. According to survey findings, the primary human resource challenges include a shortage of trained nationals with the vocational skills required for most logistics jobs (40\%), succession planning (36\%), executive recruitment (36\%), and a lack of consistent, credible training and logistics standards (28\%), as illustrated in Fig. 4. Without action, the skills gap will widen as the logistics sector expands. Increasing technologies may help logistics organizations lessen their reliance on foreign labour. Technologies will continue to advance; it may also reduce the total demand for labour (Benayoune, 2018).

On the one hand, the availability of a cheap labour force may slow the adoption of new technologies. On the other hand, technological adoption is predicted to 
lower overall demand for labour (mainly expatriates), improve the logistics industry's image, and generate high-quality employment to attract new entrants. For instance, the exponential rise of e-commerce is straining distribution centers warehouses. As a result, technology adoption will be a critical differentiator to remain competitive as the case sector becomes more technologically focused, the workforce transitions from physically demanding jobs to those that require more ability and expertise. As a result, logistics jobs be-come more appealing to the local workforce.

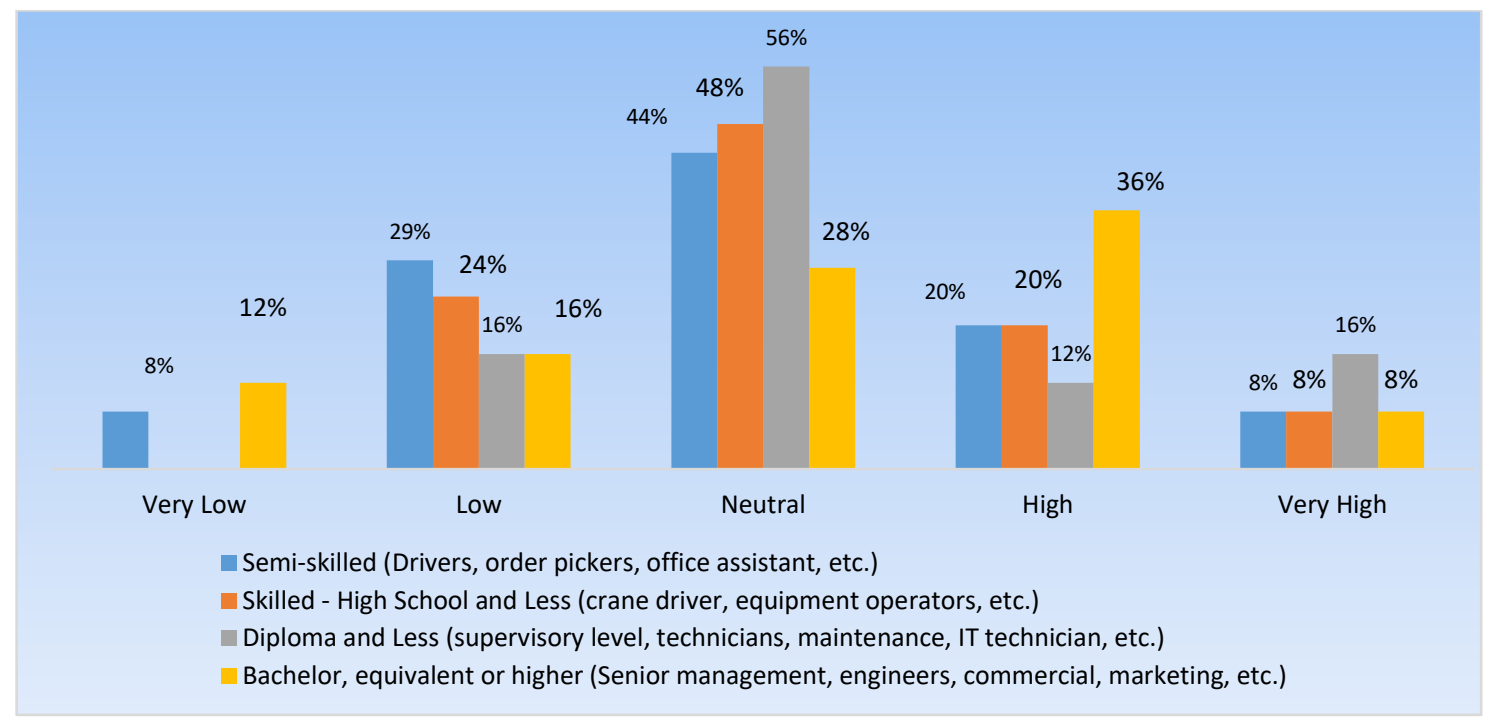

Fig. 4: The availability of suitably qualified personal in Oman.

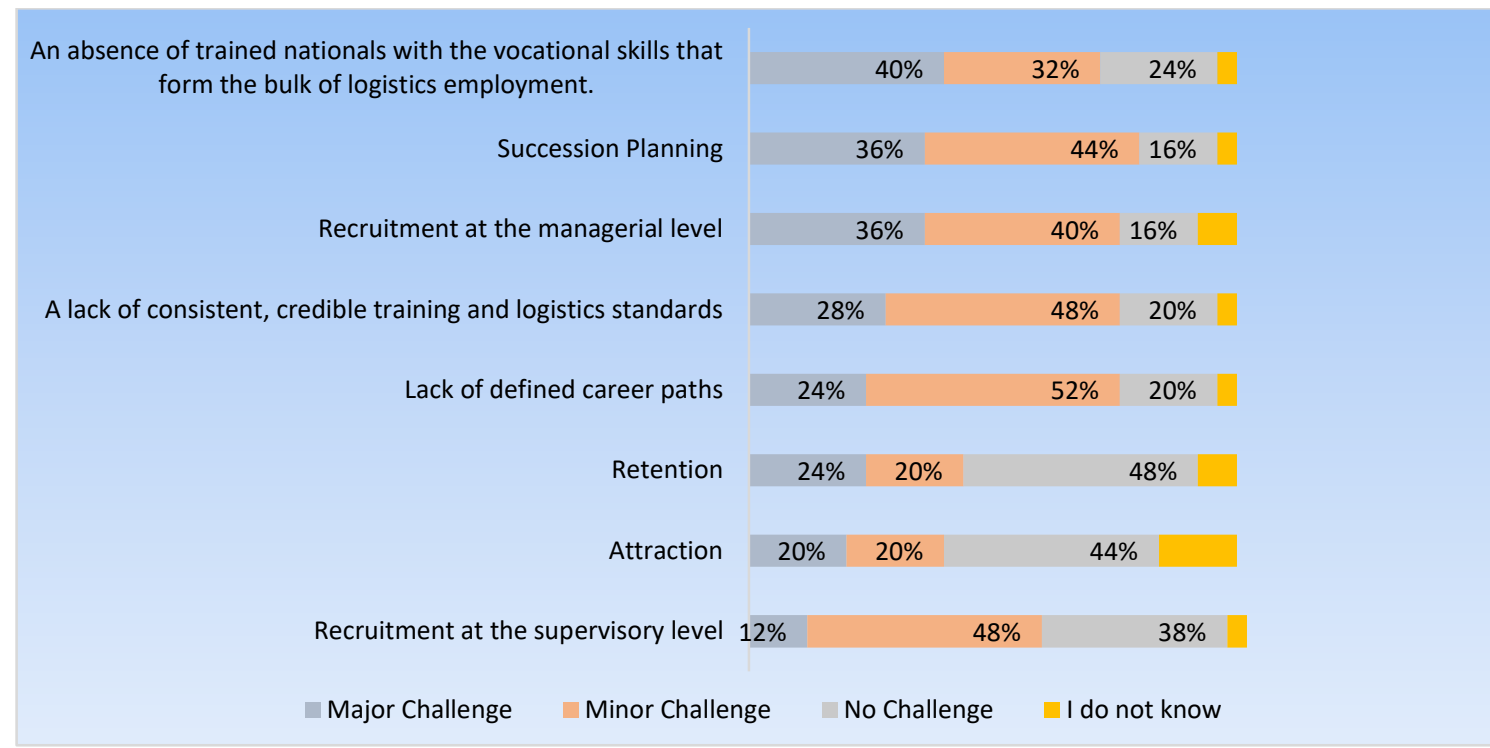

Fig. 5: Human resources challenge facing logistics firms.

As far as recruitment is concerned, $36 \%$ of respondents have trouble finding the required skills and experience to fill logistics-related roles, uncompetitive compensation packages (20\%), and the lack of awareness of the logistics function (20\%). The results are in line with the SOLS (2015) report. Regarding strategies to address the skills requirements, most respondents $(45 \%)$ selected re-skilling existing employees to meet new job requirements and $(21 \%)$ chose to outsource some business functions to external contractors. The last option is chosen $(15 \%)$ is hiring new staff with skills relevant to new technologies Fig. 7a. The main barriers to address the skills requirements identified by respondents include Lack of appropriate education and training (40\%), Lack of proper education and training (32\%), no barrier (32\%) and $(28 \%)$ of respondents said they are unaware of relevant skills as shown in Fig. 7b. Most respondents (48\%) agree that all stakeholders (government, employer and individual) should share the cost of re skilling and up skilling Fig. 7c. 


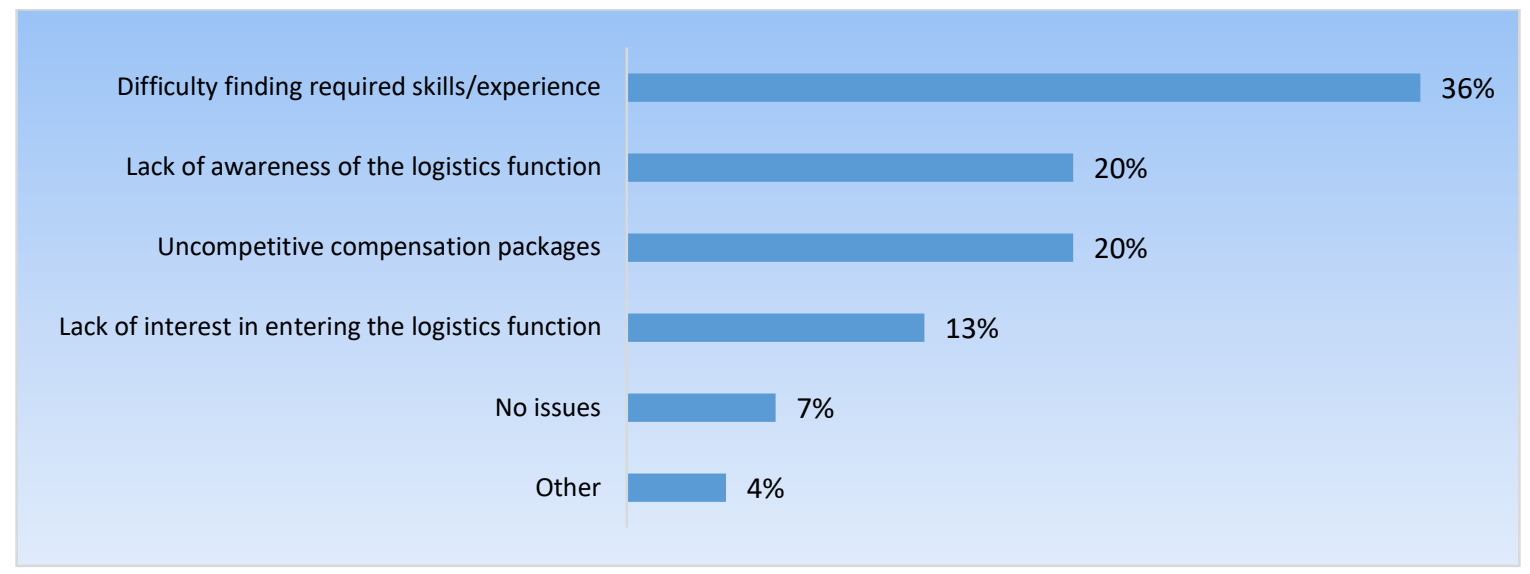

Fig. 6: Recruitment issue(s) concerning logistics workers.

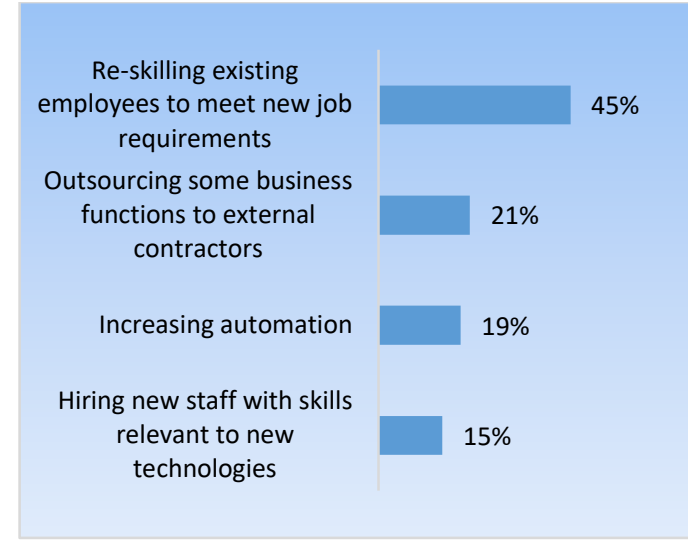

(a) Strategy to close the digital gap.

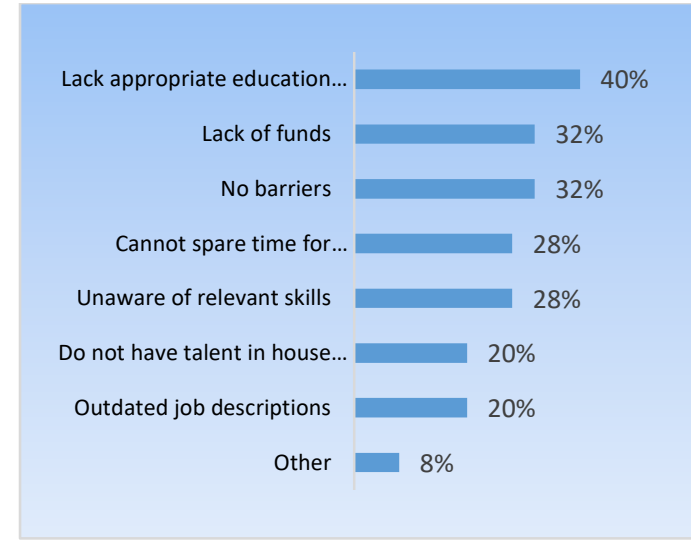

(b) Critical barriers to upskilling current employees.

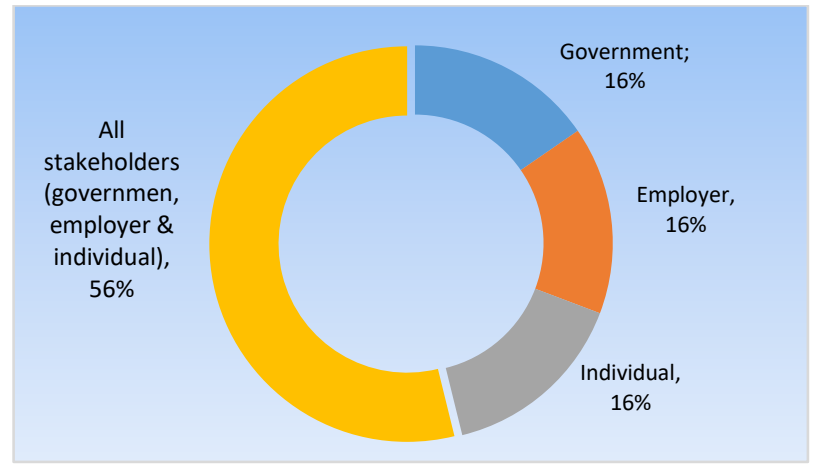

(c) Who should bear the costs of reskilling and upskilling employees.

Fig. 7 (a, b and c): Skills development and strategies to bridge the digital gap.

Most respondents (52 per cent) identified disconnect between logistics firms' needs and educational output. When asked about curricula, only $16 \%$ of respondents thought that courses match industry needs. In comparison, $20 \%$ of respondents thought that graduates possess the necessary core skills, while $28 \%$ agreed that graduates possess essential digital skills (Fig. 8). Internships provide students with sufficient exposure to the work environment, according to $40 \%$ of respondents. The education and vo- cational systems, in general, are not as responsive to market needs as they should be.

\section{DISCUSSION:}

The survey findings indicated a shortage of skills and a mismatch between academic and industrial needs. To close the gap, educational and vocational institutions must evaluate their offerings and create a uniform set of logistics skill requirements to better prepare graduates for entry-level work. 


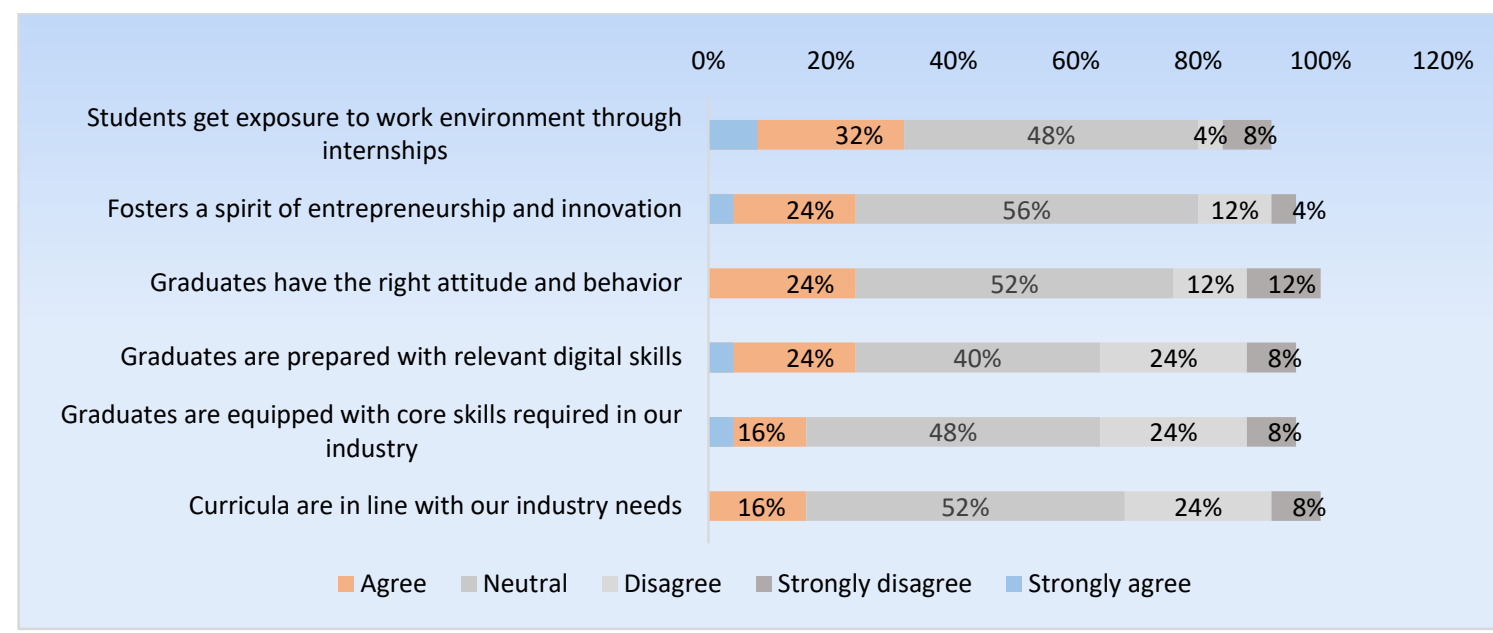

Fig. 8: The education and vocational training system.

Additionally, the results revealed a need for up skilling and life-long learning. As a result, educational and vocational institutions should transition to multimodal and flexible modes of instruction, such as elearning, simulation-based learning, and on-the-job training. This should also be reflected in skill development policies (Hamid, 2021). Additionally, the survey findings indicated a lack of in-demand jobs and future skill requirements. To assist the industry in making the transition to Logistics 4.0, the government is expected to build a skills framework that includes up-to-date information on logistics employment, training, and education. Additionally, the government is expected to support and facilitate collaboration between industry, academia, and government. Oman can learn a few lessons from Singapore's Industry Transformation Maps (ITMs) (ITM, 2021).

Each ITM includes a growth and competitiveness strategy that details the impact of technology on various industries, career paths, and the skills required and re skilling possibilities. The Oman Logistics Association (OLA) already has a Skills Unit (SSU). This unit is believed to be crucial in establishing a demand-driven skill development system. This program will serve as a clearinghouse for logistics-related skill requirements and occupational norms (Oman Times, 2019). However, this program is new, and its impact is unknown. Another government-led project is establishing a virtual collaborative platform to foster industry-academia collaboration. This virtual platform enables industry, academia, and government collaboration on Industry-related research and innovation. In 2020, Oman's Ministry of Higher Education, Research, and InnoUniversePG I www.universepg.com vation (MOHERI) announced a program named "Eidaad" to connect academia's output with industry needs by pre-graduating students with future skills and applied technical capabilities. This curriculum consists of a full academic year of blended internships. These initiatives, however, are relatively new. It is too early to determine their efficacy. It is worth noting that investments in Logistics 4.0 would increase the country's logistics and supply chain efficiency and Oman's worldwide logistics ranking, following its logistics strategy 2040 and national digital strategy.

\section{CONCLUSION:}

Oman's logistics sector is thriving and expanding rapidly and is predicted to contribute nearly $12 \%$ of the country's GDP by 2040. The purpose of this study was to investigate and assess senior managers' and experts' perspectives on the influence of Logistics 4.0 adoption on skill requirements. This study implies that those with lower levels of education and those in low-skilled employment will be disproportionately affected by technological progress. This type of work is typically filled by migrant labourers ready to work for lesser wages than citizens. As a result, boosting the country's reliance on the migrant worker through technology may minimize the country's over-reliance on the foreign workforce. Nonetheless, the low cost of labour may impede technology adoption. As the sector becomes more technologically advanced, the crew is anticipated to transition from physically challenging occupations to those requiring more skill and aptitude. As a result, logistics jobs become more appealing to the local workforce. Industrial cyber security management, data management and security, data analytics, digital 
marketing, knowledge of logistics functions and supply chain management, and programming \& coding and ICT will become increasingly relevant. Soft skills such as creativity, communication, problem-solving, and critical thinking will, as expected, remain necessary. However, the considerable skills (technical and soft) now needed in Oman's local market are data analytics, digital marketing, lifelong learning, creativity and innovation, programming and coding, and industrial cyber security. Additionally, the findings indicate a skills gap and an insufficient supply of skills. Most logistics companies have difficulty recruiting qualified applicants to fill logistics positions. Retraining current employees to match new job standards or to outsource specific business tasks to external contractors is the primary way logistics organizations solve skills shortages. However, there is a continuing shortage of adequate education and training and a mismatch between industrial demands and educational output. To assist the industry in making the transition to Logistics 4.0, the government is expected to build a skills framework that includes up-to-date information on logistics employment, training, and education. Additionally, the government is expected to support and facilitate collaboration between industry, academia, and government. The article provides more empirical data to address a knowledge gap in this sector. It helps our current understanding of skill requirements and the future of work in the industry 4.0 era. The authors believe that these findings can be applied to other sectors of the Omani economy and elsewhere. However, this study's data was com-piled from each firm's responses from a single responder. Likewise, respondents may be unfamiliar with all the research topics being explored. This can be viewed as a constraint. The second constraint is the low response rate. As a result, future researchers can expand the sample size and collect data from different respondents from the same firm to further investigate and enhance the findings.

\section{ACKNOWLEDGEMENT:}

Thanks are to the International Maritime College for financial support. The authors also acknowledge ASYAD Group for its support in sending out the survey and following up with respondents. Likewise, the authors are grateful to the survey respondents. Without their insights, this study would not have been possible.

\section{CONFLICTS OF INTEREST:}

The authors have no conflicts of interest in publishing this research study.

\section{REFERENCES:}

1) Acemoglu, D., and Restrepo., P. (2016). Automation and Unemployment: A Task-based Search Model. Work in progress, MIT

2) Alemu, A. E., Hamid, A. A., Fitri, N. S., Rahman, B. A., \& Al Wadhahi, Y. S. S. (2021). Teaching Nexus to Logistics Competence and Skills: An Exploratory Study on Logistics sector from the perspective of Mana-gers in Oman. Psychology And Education, 58(5), 4706-4720.

3) Arntz, M., Gregory, T., Zierahn, U., (2016). The risk of automation for jobs in OECD countries: A comparative analysis. Tech. Rep. 189, OECD Social, Employment and Migration Working Papers.

4) Autor, D., (2015). Why Are There Still So Many Jobs? The History and Future of Workplace Automation. Journal of Economic Perspectives, 29(3), pp. 3-30.

5) Bag, S., Telukdarie, A., Pretorius, J.H.C. Shivam Gupta, S. (2021). Industry 4.0 and supply chain sustain-ability: framework and future research dire-ctions. Benchmarking: An International J. https://doi.org/10.1108/BIJ-03-2018-0056

6) Bakhshi, H., Downing, J.M., Osborne, M.A., and Schneider, P. (2017). The future of skills: Employment in 2030. Available Online at:

https://www.caasitechacademy.com/media/thefutur eofskills.pdf

7) Bonfield, C., Salter, M., Longmuir, A., Benson, I., and Adachi, (2020). Transfor-mation or evolution? Education 4.0, teaching and learning in the digital age. Higher Education Pedagogies, 5(1), 223-246, https://doi.org/10.1080/23752696.2020.1816847

8) Bowles, J. (2014). The Computerization of European Jobs. Bruegel, Brussels.

9) Benayoune. A, (2018). Towards Effective Human Capital Development for the Logistics Industry. International Journal of Trade, Economics and Finance, 9(4).

10) CBO, (2019). Annual report of central bank of Oman. Retrieved from -

https://cbo.gov.om/sites/assets/Documents/English/ Publications/AnnualReports/AnnualReport2019En glish.pdf 
11) Crowley SS, Sikder MR, and Dhar A. (2022). CAMEL- based performance of a foreign bank in Bangladesh: a study on commercial bank of Ceylon, Int. J. Manag. Account. 4(1), 01-11. https://doi.org/10.34104/ijma.022.01011

12) Dembińska, I. (2018). Smart logistics in the evolution of the logistics. European Journal of Service Management. 3(2), Pp.123-133.

13) Drath, R. and Horch, A. (2014). Industrie 4.0: Hit or Hype? Ind. Elect. Maga., IEEE, 8, 56-58. https://doi.org/10.1109/MIE.2014.2312079

14) Ehlers, D., and Kellermann, S.A. (2019). Future skills - The future of learning and higher education. Results of the international Delphi survey.

15) Ehrhardt and Partner, (2016). Recognizing chances. Taking changes. Logistics 4.0 - smart, connected, digital. Available at:

https://www.warehouse-logistics.com/57/3/8219/r ecognizing-chances-taking-changes-logistics-40\% E2\%80\%93--smart,-connected,-\%20digital-html

16) Ellingrud, K., Gupta, R. and Salguero, J. (2020). operationally intensive companies have entered a new wave of automation and digitization. That will have a big impact on the skills they need to remain competitive. Available Online at:

https://www.mckinsey.com/business-functions/op erations/our-insights/building-the-vital-skills-for-t he-future-of-work-in-operations

17) Ezzat, M., Kassem, S. and Abd Elkader, M. (2019). Logistics 4.0: Definition and Historical Background. Available Online at: https://doi.org/10.1109/NILES.2019.8909314

18) Brunello, G and Wruuck, P., (2019). Skill Shortages and Skill Mismatch in Europe: A Review of the Literature. http://ftp.iza.org/dp12346.pdf

19) Frey, B., and M.A. Osborne. A. (2013). The Future of Employment: How Susceptible is Jobs to Computerization? University of Oxford.

20) FTA, (2019). FTA Logistics Skills Report. https://logistics.org.uk/CMSPages/GetFile.aspx?gu id=8afc692b-a971-4357-be45-40281ab02c30\&lan $\mathrm{g}=\mathrm{en}-\mathrm{GB}$

21) Hamid A. (2021). Supply chain integration and health firms operational performance implycations for underdevelopment countries. IJIEPR, 32(1), 143-157.

http://ijiepr.iust.ac.ir/article-1-1018-en.html

22) Herceg, V., Kuč, V., Mijušković, V.M., and Herceg, T. (2020). Challenges and Driving Forces for Industry 4.0 Implementation. Sustainability, 12, 4208. https://doi.org/10.3390/su12104208

23) ITM, (2021). The Ministry of Trade and Industry. Available Online at:

https://www.mti.gov.sg/Transforming-Industries/F or-Industries

24) Magruk, A. (2016). The Internet of things as the future technological trend of the innovative development of logistics. Research in Logistics and Production, 6(1), pp. 15-24.

25) Maisiri, W., H. Darwish, H., and van Dyk, L. (2019). An Investigation of Industry 4.0 Skills Requirements. S. Afr. J. Ind. Eng, 30(3). http://dx.doi.org/10.7166/30-3-2230

26) MGI, (2019).Automation in logistics: big opportunity, bigger uncertainty.

27) Mogos, M. Eleftheriadis, R., and Myklebust, O. (2019). Enablers and inhibitors of Industry 4.0: results from a survey of industrial companies in Norway. Procedia CIRP, 81, 624-629. https://doi.org/10.1016/j.procir.2019.03.166

28) Moldabekova, A., Philipp, R., Satybaldin, A., and Gunnar Prause, G. (2012). J. of Asian Finance, Economics and Business, 8(1), 145-156. https://doi.org/10.13106/jafeb.2021.vol8.no1.145

29) PwC, (2016). The future of the logistics industry. Available Online at:

https://www.pwc.com/sg/en/publications/assets/fut ure-of-the-logistics-industry.pdf

30) PwC, (2018). Will robots really steal our jobs? An international analysis of the potential longterm impact of automation. Available Online at: https://www.pwc.co.uk/economic-services/assets/ international-impact-of-automation-feb-2018.pdf

31) PwC, (2021). Intelligent automation: The future of digitalization in organizations.

https://www.pwc.in/assets/pdfs/consulting/technol ogy/emerging-technologies/intelligent-automation/ intelligent-automation-the-future-of-digitalisationin-organisations.pdf

32) Rahman KS. (2021). Implications of green management practices in the RMG industries of Bangladesh- an environmental sustainability perspective, Int. J. Manag. Account. 3(6), 122129. https://doi.org/10.34104/ijma.021.01220129

33) Schröder-Hinrichs, J. U., Song, D. W., Fonseca, T., Lagdami, K. and Loer, K. (2019). Transport 2040: Automation, Technology, Employment The Future of Work. https://doi.org/10.21677/itf.20190104 
34) Schwab, K., (2016). The Fourth Industrial Revolution: What It Means and How to Respond. World Economic Forum.

https://www.weforum.org/agenda/2016/01/the-fo u rth-industrial-revolution-what-it-means-and-how-t o-respond

35) SOLS, (2015). The Sultanate of Oman Logistics Strategy 2040 Report.

36) Strange, R., and Zucchella, A. (2017). Industry 4.0, Global Value Chains and International Business. Multinational Business Review. 25. 00-00. https://doi.org/10.1108/MBR-05-2017-0028

37) TANFEED, (2016). The National Program for Enhancing Economic Diversification Handbook. Available Online at:

http://tanfeedh.gov.om/TANFEED-HAND-BOOK -2017-en.pdf

38) Times of Oman, (2019). Available Online at: https://timesofoman.com/article/2404957/oman/de dicated-skills-unit-for-logistics-sector-to-co me-upin-oman
39) WEF, (2017). The Future of Jobs and Skills in the Middle East and North Africa: Preparing the Region for the Fourth Industrial Revolution. Available Online at: http://www3.weforum.org/docs/WEF_EGW_FO J_MENA.pdf

40) WEF, (2020). The Future of Jobs Report. http://www3.weforum.org/docs/WEF_Future_of Jobs_2020.pdf

41) Winkelhaus, S., and Grosse, E. (2020). Logistics 4.0: a systematic review tow-ards a new logistics system. International J. of Production Research, 58(1), pp. 18-43. https://doi.org/10.1080/00207543.2019.1612964

42) Pfeiffer, S. (2017). The Vision of "Industrie 4.0" in the Making - a Case of Future Told, Tamed, and Traded. Nanoethics,11, 107-121 https://doi.org/10.1007/s11569-016-0280-3

43) World Bank Group, (2019). Vietnam Development Report 2019: Connecting Vietnam for Growth and Shared Prosperity. https://openknowledge.worldbank.org/bitstream/ $\underline{\text { handle/ }}$

Citation: Benayoune A, Hamid AA, Rahman NSFA, Kalbani KA, and Slimi Z. (2021). Logistics 4.0 skills requirements: evidence from a developing country, Can. J. Bus. Inf. Stud., 4(2), 24-36. https://doi.org/10.34104/cjbis.022.024036 @ @ 